\title{
Introdução aos excertos de Marx sobre James Mill (1844): ou sobre o reconhecimento
}

\author{
Introduction to the excerpts of Marx on James Mill (1844): on \\ recognition
}

\author{
Luiz Philipe de Caux \\ luizphilipedecaux@gmail.com \\ (Universidade Federal de Minas Gerais, Minas Gerais, Brasil)
}

\begin{abstract}
Resumo: 0 artigo apresenta e justifica de forma sucinta a traducão dos "Excertos do livro de James Mill 'Éléments d'économie politique'”, escritos por Karl Marxà época dos Manuscritos Econômico-Filosóficos (1844). Nestas anotações, além de se debruçar sobre os temas tratados nos Manuscritos (dinheiro, alienação, ser genérico, trabalho, propriedade privada etc.), Marx trata de forma única no corpo de sua obra o tema do reconhecimento como tomado de Hegel, conceituando as relações no interior da sociedade civil como relações conflituosas de reconhecimento. 0 texto possui, assim, implicações tanto para a interpretação de Marx quanto como contribuição para a teoria do reconhecimento contemporânea.
\end{abstract}

Palavras-chave: Marx; Hegel; Honneth; reconhecimento; alienação.
Abstract: The article presents and justifies briefly the translation of the "Comments on James Mill, 'Éléments d'économie politique'", written by Karl Marx at the time of the Economic and Philosophical Manuscripts (1844). Besides exploring the themes treated in the Manuscripts, Marx addresses the theme of recognition as elaborated by Hegel in an unique way along the corpus of his work, conceiving the relations inside the civil society as conflictual relations of recognition. The notes have thus implications to the interpretation of Marx as well as a contribution to the contemporary theory of recognition.

Keywords: Marx; Hegel; Honneth; recognition; alienation.

DOI: http://dx.doi.org/10.11606/issn.2318-9800.v21i1p93-98

O texto cuja tradução se oferece a seguir é de pouco conhecimento não apenas dos leitores de língua portuguesa, mas dos leitores de Marx em geral. A pouca atenção que despertou até recentemente não deve, no entanto, deixar enganar sobre a relevância de sua posição no quadro geral da obra e do desenvolvimento do pensamento marxiano. Incluídos no primeiro volume de complementos da MarxEngels-Werke (MEW 40), ${ }^{1}$ os “Excertos” se encontram originalmente em um caderno no

1 A tradução tomou como base a edição da MEW (Marx, K. „Auszüge aus James Mills Buch «Élémens d'économie politique»". In: Marx, K; Engels, F. Marx-Engels-Werke. Ergänzungsband I. Berlim: Dietz, 1968, pp.443-463), com consulta à edição incluída como anexo no volume dos Manuscritos na coleção Studienbibliothek da Suhrkamp, por sua vez extraída da MEGA, e que recebeu do editor Michael Quante o título “A concepção de reconhecimento” (Marx, K. „Das Konzept der Anerkennung“. In: Marx, K. Ökonomisch-philosophische Manuskripte. Kommentar von Michael Quante. Frankfurt a.M.: Suhrkamp, 2009, pp.188-208). 
qual Marx trabalhou no verão e no outono de 1844 em Paris. Trata-se de comentários tecidos a partir da leitura da tradução francesa dos Elements of Political Economy de James Mill, publicados em Londres em 1821. Segundo os trabalhos de edição mais recentes, tudo leva a crer que foram escritos por Marx logo depois da redação dos cadernos que compuseram os Manuscritos Econômico-Filosóficos (cf. Quante, 2009, p.374). Citados por Axel Honneth em sua obra central (Honneth, 2009, p.231, nota de rodapé n.4), os “Excertos" passaram nos últimos anos a despertar a atenção da pesquisa filosófica no interior dos debates em teoria da justiça ${ }^{2}$ e no desenvolvimento da teoria do reconhecimento. ${ }^{3}$ Com efeito, aqui Marx não apenas se dedica novamente aos temas que compõem os Manuscritos (dinheiro, alienação, ser genérico, trabalho, propriedade privada etc.), como elabora, como talvez em nenhum outro momento de sua obra, reflexões sobre as relações de produção, troca e consumo no interior da sociedade civil-burguesa enquanto relações de reconhecimento recíproco. A compreensão dessas relações como relações de reconhecimento permitem a Marx tanto criticar sua forma capitalista enquanto essencialmente alienada quanto pensar, a partir da forma lógica do reconhecimento, uma concepção normativa de um "estado positivo de não alienação” (Quante, 2009, p.278). Michael Quante não apenas sustenta que neste texto "Marx emprega o reconhecimento como critério da crítica" (idem, p.275), como chega mesmo a afirmar que essa "análise dada em seus escritos de Paris em 1844 é ainda o pano de fundo em geral da crítica da economia política” (Quante, 2013, p.724) em O Capital. Num contexto em que não apenas a teoria do reconhecimento, em particular com Honneth, mas também a sua crítica ganham espaço nas discussões em filosofia e teoria social e política no Brasil, parece oportuno tornar acessível em língua portuguesa a potência crítica do jovem Marx ao se debruçar sobre o tema. Também a interpretação do seu pensamento e a de sua recepção de Hegel, tanto da Fenomenologia quanto da Filosofia do Direito, ganham novos aportes. Por fim, os “Excertos" apresentam elementos que podem contribuir, se não para contestar, ao menos para tornar mais controversa a apresentação, difundida por Habermas, de um Marx que, desde suas obras de juventude, reduziria a dimensão da interação à do trabalho, postulando, numa leitura materialista do conceito hegeliano de espírito, o trabalho como a única categoria de síntese social (cf. Habermas, 2014, pp.84ss).

Nas anotações marginais que faz em seu próprio exemplar da Filosofia do Direito, anotações das quais Marx não chegou a tomar conhecimento, Hegel caracteriza a figura do contrato como uma "unidade de dois que se reconhecem como livres", e o reconhecimento, ali, como essa “unidade abstrata” (Hegel, 1989,

2 Por exemplo, em Daniel Brudney (Brudney, 1998; 2010, pp.151-188; 2014, pp.450-471).

3 Em particular, por Michael Quante (Quante, 2011, pp.211-238; Quante, 2013, pp.713-727), mas também por Emmanuel Renault (Renault, 2013, pp.699-711, em especial pp.700-705). 
p.156 (anotação marginal ao §72)). Combinando livremente a simetria formal da relação de reconhecimento descrita pelo Hegel maduro nas relações contratuais de troca no interior da sociedade civil-burguesa com a assimetria material das relações de senhorio e servidão, que Hegel desenvolve na Fenomenologia do Espírito como o movimento através do qual o reconhecimento vem primeiro a ter lugar, Marx aponta, por um lado, para uma forma de reconhecimento de pretensões mais elevadas do que aquela encontrada por Hegel e, por outro, para o fato de que a instauração do direito representa apenas uma síntese precária que oculta sem de fato dissolver as relações de dominação e o conflito social estruturado como uma luta por reconhecimento.

Chitty comenta que, neste texto, "Marx organiza sua oposição entre a sociedade de mercado do presente e a sociedade comunista do futuro ao redor do contraste entre a primeira dessas formas de reconhecimento", isto é, o reconhecimento do outro como pessoa de direito e proprietário, aquele reconhecimento formal que estrutura o contrato, "e uma versão universalizada da segunda", ou seja, de um "reconhecimento do outro como um ser com necessidades" (Chitty, 2013, p.691). ${ }^{4}$ E completa que "enquanto para Hegel a propriedade privada e o reconhecimento mútuo como proprietários supera nossa alienação mútua e da natureza, para Marx eles a criam" (idem, p.695). Isso porque criam justamente a possibilidade (ou antes, a necessidade) de que as carências dos parceiros de interação não sejam consideradas concretamente, mas apenas num sentido abstrato, podendo ser, portanto, tratadas reciprocamente apenas de modo instrumental (tratamento no qual cada um dos contratantes instrumentaliza sua própria carência e assume a postura típica do servo). Para Marx, no entanto, "a carência de uma coisa é a prova mais evidente e irrefutável de que a coisa pertence à minha essência" (Marx, 2016, pp.153-4). Deixando de reconhecer a dependência recíproca de nossas carências, alienamo-nos daquilo que produzimos para a troca, daqueles com quem trocamos, de nós mesmos e, por fim, de nossa existência como membros de uma espécie que assegura sua sobrevivência pela divisão do trabalho. Se "no capitalismo, demonstro meu autorrespeito afirmando

4 Nesse sentido, Daniel Brudney explica numa leitura analítica: "Reconhecimento é aqui algo exigente. Não é o bastante que B registre que A está produzindo algo que B irá usar. Isso poderia ser obtido sob o capitalismo. Também não é suficiente que $B$ registre que $A$ está produzindo algo que ele tenciona que $B$ utilize, no que a utilização por $B$ seja instrumental para algum outro objetivo que $A$ tenha, como por exemplo, que $A$ tencione que $B$ utilize seu produto porque assim não apenas $B$, mas também $C$ e $D$ comprarão o produto de $A$, tornando-o rico. Tampouco é suficiente que $B$ registre que para $A$ o uso de $B$ do produto de $A$ é o ponto final do objetivo de $A$ ao produzir. Pois $B$ pode não se importar com esse fato. B precisa tanto registrar esse fato como, como Marx coloca, "afirmá-lo". Além disso, tanto A quanto B precisam ver o processo de produção e de consumo como fundamental em si. Eles precisam ver a produção para outros não como uma atividade trivial, mas sim como o modo básico como os seres humanos realizam sua natureza: sob condições próprias, ela é a vida boa" (Brudney, 1998, p.152.)

5 Do que não se deve concluir que antes do reconhecimento que fundamenta e estrutura a forma social da propriedade privada pode ter havido um estado de não-alienação: "O estado inicial do homem não é, portanto, a não alienação, mas sim a pré-alienação e a indiferenciação" (Quante, 2009, p.258). 
minha não-dependência dos outros", Marx tem em mente uma sociedade na qual, pelo reconhecimento, afirmo "meu modo específico de dependência" (Brudney, 1998, p.172). Pois a independência aparente do proprietário privado se constitui num sistema real de "entrelaçamento omnilateral da dependência de todos" (Hegel, 1989, p.353, § 199), para usar uma expressão de Hegel. ${ }^{6}$ Não se trata, portanto, de superar a dependência material recíproca, mas de dela se reapropriar, fazendo da relação de produção, troca e consumo uma relação mediada pelo objeto na qual nos afirmamos mutuamente em nossas carências concretas: "Nossas produções seriam assim vários espelhos desde os quais nossa essência luziria em reflexo" (Marx, 2016, p.160).

Se, no entanto, a proposição positiva de um estado de superação da alienação através de uma forma universalizada de reconhecimento das carências materiais concretas pode soar excessivamente utópica a um leitor da segunda década do século $\mathrm{XXI},{ }^{7}$ a crítica do mercado capitalista, para falar com Honneth, enquanto esfera de reconhecimento, parece, como nunca, atual. Nas palavras de Quante,

Marx quer então mostrar, e aqui está a renúncia crítica a Hegel, que a derrogação da escravidão em uma ordem jurídica que representa uma estrutura simétrica de reconhecimento é apenas a supressão [Aufhebung] da superfície ou da forma fenomênica da autorrelação contraditória, e não é de forma alguma a dissolução dessa contradição mesma. (Quante, 2009, p.292)

A relação de dominação apenas prossegue por outros meios no interior do mercado capitalista, bem como a luta por reconhecimento: "A medida do poder sobre teu objeto que atribuo ao meu precisa, no entanto, para se tornar um poder efetivo, do teu reconhecimento. Nosso reconhecimento recíproco sobre o poder recíproco dos nossos objetos é, porém, uma luta" (Marx, 2016, p.158). Essa luta que tem lugar em cada relação de troca, incluindo, claro, a da troca da própria força de trabalho, não é passível de ser superada pelos princípios imanentes à troca mesma, pois nela, necessariamente,

procuramos nos enganar mutuamente pelas aparências e o mais hábil ludibria o outro. Quem ludibria o outro, isso é, do ponto de vista do todo da relação, um acaso. 0 ludíbrio ideal, visado, acontece de ambos os lados, isto é, cada um dos dois ludibriou o outro em seu próprio juízo. (idem, ibidem)

6 Cf., também, Marx em O Capital: "Nossos possuidores de mercadorias descobrem, assim, que a mesma divisão do trabalho que os transforma em produtores privados independentes também torna independente deles o processo social de produção e suas relações nesse processo, e que a independência das pessoas umas das outras se consuma num sistema de dependência material [sachlich] universal" (Marx, 2013, p.182).

7 Em analogia com a especulação acerca de um eventual quarto princípio de reconhecimento, proposto por Nancy Fraser, Honneth poderia afirmar que tal forma de reconhecimento proposta por Marx não se encontra presente na "estrutura normativa das sociedades capitalistas", não estando, portanto, acessivel a uma teoria do reconhecimento que proceda reconstrutivamente (cf. Honneth, 2003, pp.161ss); afirmação da qual Marx certamente não discordaria. 
Como Marx retomaria em O Capital, trata-se de uma antinomia real, "um direito contra outro direito, ambos apoiados na lei da troca de mercadorias" (Marx, 2013, p.309). Sem que nisso se perca a fertilidade do conceito de reconhecimento em geral para a articulação de uma teoria crítica da sociedade, trata-se de um questionamento radical da própria possibilidade de que os princípios de reconhecimento imanentes e constitutivos da ação econômica no mercado, a saber, a igualdade formal da troca e a noção de mérito que orienta a distribuição do produzido, possam servir de fulcro para a crítica dessas relações mesmas. ${ }^{8} \mathrm{Ou}$, em termos marxianos, que o valor possa servir de critério para sua própria crítica.

Por fim, gostaria de ressaltar algumas opções de tradução. Seguindo a tradução de Rubens Enderle (em Marx, 2013), traduzo naturwüchsig por "naturalespontâneo", que me parece captar bem a nuance do termo em relação ao mero "natural". Nationalökonomie é traduzido como "Economia Política", que repercute no adjetivo ("político-ecônomico(a)") e no substantivo ("economista político") derivados. Compreendendo que, no uso feito por Marx, Entäußerung e Entfremdung são sinônimos, ${ }^{9}$ verto ambos por "alienação", demarcando, todavia, a diferença do original através de um asterisco $\left({ }^{*}\right)$, a fim de preservar a possibilidade de interpretações distintas. Onde o verbo "alienar" e seus adjetivos e substantivos derivados forem seguidos de um asterisco ("trabalho alienado*"), trata-se, no original, do alemão entfremden; na ausência do asterisco, de entäußern. Em que pese a recomendação da excelente e decisiva revisão com que o texto contou e pela qual sou extremamente grato, mantive essa opção, pela qual assumo a responsabilidade.

\section{Referências:}

Brudney, D. (1998). Marx attempt to leave Philosophy. Cambridge: Harvard UP. . (2010). "Producing for others”. In: Schmidt Am Busch, H.-C.; Zurn, C. (eds.). The Philosophy of Recognition: Historical and Contemporary Perspectives. Lanham: Lexington Books, pp.151-188.

. (2014). "The young Marx and the middle-aged Rawls". In: Mandle, J.; Reidy, D. (eds.). A Companion to Rawls. Chicester: Wiley Blackwell, pp.450-471. Chitty, A. (2013). Recognition and Property in Hegel and the Early Marx. Ethical Theory and Moral Practice, 16 (4), pp.685-697.

Habermas, J. (2014). Conhecimento e interesse. Tradução de Luiz Repa. São Paulo:

8 Como segue propondo Honneth em sua obra mais recente, Honneth, 2011.

9 Essa é igualmente a visão de Michael Quante: "Na Fenomenologia, Hegel fala da Entäußerung [na tradução brasileira de Paulo Meneses, traduzida por 'extrusão', L.Ph.C] da consciência-de-si, que diferencia de sua Entfremdung. Marx, ao contrário, equipara Entäußerung e Entfremdung". Cf. Quante, 2009, p.237. 
UNESP.

Hegel, G. W. F. (1989). Grundlinien der Philosophie des Rechts (=Werke Band 7). Frankfurt a.M.: Suhrkamp.

Honneth, A. (2003). “Redistribution as Recognition: A Response to Nancy Fraser”. In:

Fraser, N.; Honneth, A. Redistribution or Recognition? A Political-Philosophical Exchange. London; New York: Verso.

- (2009). Luta por reconhecimento: a gramática moral dos conflitos sociais. $2^{a}$ ed. Tradução de Luiz Repa. São Paulo: Editora 34.

. (2011). Das Recht der Freiheit: Grundriß einer demokratischen Sittlichkeit. Berlim: Surhkamp.

Marx, K. (2009). Ökonomisch-philosophische Manuskripte. Kommentar von Michael Quante. Frankfurt a.M.: Suhrkamp.

. (2013). O Capital: Crítica da Economia Política. Livro I. Tradução de Rubens Enderle. São Paulo: Boitempo.

Quante, M. (2009). “Kommentar”. In: Marx, K. Ökonomisch-philosophische Manuskripte. Kommentar von Michael Quante. Frankfurt a.M.: Suhrkamp, pp.209411.

. (2011). "Recognition as the Social Grammar of Species Being in Marx". In: Ikäheimo, H.; Laitinen, A. (eds.). Recognition and Social Ontology. Leiden: Brill, pp.211-238.

(2013). Recognition in Capital. Ethical Theory and Moral Practice, 16 (4), pp.713-727.

Renault, E. (2013). Three Marxian Approaches to Recognition. Ethical Theory and Moral Practice, 16(4), pp.699-711. 